\title{
El Castillo Interior o Las Moradas, de Santa Teresa
} de Jesús*

Francisco Bobadilla Rodríguez **

Universidad de Piura

francisco.bobadilla@udep.pe

\section{Introducción}

Canta Teresa de Jesús ha sido, desde mis años de universitario, uno de los personajes de la $\checkmark$ cristiandad que más he admirado. Pasaron los años y los avatares de la vida me llevaron a descubrir la riqueza de su vida, lo sugerente de sus escritos, y el atractivo de la vida cristiana sin ahogos ni asfixias. Su Libro de la vida es uno de los textos al que vuelvo reiteradamente. Allí descubrí que la gran santa que conocemos tomó la determinación de ser una buena hija de la Iglesia alrededor de los cuarenta años, después de quedar tocada al mirar a un Cristo gibado, encogido por el dolor de la pasión y por los pecados de los hombres y mujeres de

\footnotetext{
* El presente texto es una adaptación de la ponencia presentada en el coloquio "Santa Teresa de Jesús, vida y proyecciones”. Este evento se llevó a cabo los días miércoles 14 y jueves 15 de octubre de 2015 en el Campus Lima de la Universidad de Piura.

** Francisco Bobadilla Rodríguez es magíster en Derecho, con mención en Derecho Civil, por la Pontificia Universidad Católica del Perú, licenciado en Ciencias de la Información por la Universidad de Piura y doctor en Derecho por la Universidad de Zaragoza (España). Sus temas de estudio se centran en el aspecto antropológico, ético y jurídico de la conducta humana. $\mathrm{Ha}$ colaborado en diferentes publicaciones como la revista Istmo de la Universidad Panamericana de México y en la Revista Mercurio Peruano. Ha publicado en el 2015 Pasión por la excelencia (Lima, Perú: Acres); en el 2002, Empresas con alma (Piura, Perú: Universidad de Piura) y, en el 2006, El Código Da Vinci: de la ficción a la realidad (Lima, Perú: Realidades S.A.). Actualmente, es vicerrector adjunto del Campus Lima de la Universidad de Piura y director de Centro Cultural Universitario Sama.
} 
todos los tiempos. Pensé, entonces y ahora, que siempre se está a tiempo de vivir, de volver a las ilusiones de la juventud, paso a paso, golpe a golpe, verso a verso. Se puede vivir bailando el alcatraz con esa doble vela encendida al arcángel Miguel y a Lucifer, pero una vida así no está exenta de angustia y desasosiego y terminar en más de una chamuscón.

La vida de Santa Teresa es la propia de un corazón inquieto. Este se muestra, además, frágil cuando se abandona a sus fuerzas, recio y tierno cuando acompaña a Jesús en el Calvario. Su vida y pensamiento muestran el rostro amable y exigente, a la vez, de la aventura cristiana que bien vale vivir.

Quisiera ahora glosar a pluma alzada algunos pocos textos que he entresacado de la lectura y meditación de otro de sus grandes libros titulado El castillo interior o Las moradas (Barcelona, Montaner y Simón, 1944). Texto de madurez en el que cuenta a sus hijas de religión el camino que conduce al encuentro, cada vez más íntimo, con el Señor, a través de la oración, puerta del Castillo, en donde se encuentran las moradas que conducen al encuentro del Dios-Persona, quietud y plenitud del alma. Estas glosas se expresarán a continuación, como se verá pronto, a la manera libre de la danza libre como le gustaba decir a Chabuca Granda.

\section{No Tenemos Asegurada la Santidad}

Mas una cosa os aviso: que no por ser tal y tener tal Madre estéis seguras, que muy santo era David, y ya veis lo que fue Salomón; ni hagáis caso del encerramiento y penitencia en que vivis, ni os asegure el tratar siempre de Dios y ejercitaros en la oración tan continuo y estar tan retiradas de las cosas del mundo y tenerlas a vuestro parecer aborrecidas. Bueno es todo esto, mas no basta, como he dicho, para que dejemos de temer, y asi continuad este verso y traedle en la memoria muchas veces: Beatus vir, qui timet Dominum.(p. 56)

$\mathrm{L}$ os santos lo han sabido desde el principio: no tenemos la perseverancia asegurada en el camino de santidad. Nuestra fortaleza es prestada, y solo en la medida en que 
permanecemos unidos a la Vid, en medio de las luces y sombras de la vida, se llegará a gozar del Amor de los amores. No somos flores de invernadero, estamos expuestos a los rigores del clima. Unas veces, las primaveras de la vida nos facilitan el camino; otras veces, el rigor del calor, el frío del invierno o el atardecer de los otoños nos pueden desanimar. Son momentos en los que la tentación de la otra orilla se hace presentes.

La santidad quizá esté más cerca de los niños que de los adultos y no precisamente por la inocencia de los primeros. Más bien, se debe a su audacia cuando piden y por la seguridad que les da saber que tienen una mamá y un papá que les allanan el camino. Beatus vir, qui timet Dominum; feliz aquel que desconfía de sus propias fuerzas y confía más en la ayuda del Cielo.

\section{Oración y Consideración}

Porque, a cuanto yo puedo entender, la puerta para entrar en este castillo es la oración y consideración; no digo más mental que vocal, que como sea oración, ha de ser con consideración. Porque la que no advierte con quién habla, y lo que pide, y quién es quien pide y a quién, no la llamo yo oración, aunque mucho menee los labios. (p. 18)

Caber rezar, aprender a rezar, querer rezar, necesitar rezar. Estas son expresiones que $\checkmark$ manifiestan el corazón inquieto de los hombres que no acaban de encontrar reposo hasta que, finalmente, tocan algo de esa eternidad que empieza aquí, entre el asfalto de las ciudades y el calor del hogar. Es oración, ya sea verbal o mental, que intenta ser diálogo entre personas.

No es introspección psicológica, ni siquiera simple desaguadero de un día agitado. Es diálogo, conversación íntima; saborear un texto de los salmos, una frase del Señor en los evangelios, como aquella de Pedro después de haber negado a Cristo tres veces. Con el corazón contrito y humillado le dice al Señor por tercera vez: “Tú lo sabes todo, Tú sabes que te amo" (Jn 21, 17). Sabes que soy débil, malicioso, incluso; sabes que los deseos me quedan más grandes que las obras. Sabes de los nudos de mi vida, en otras palabras, predico y no hago, quiero y no puedo, puedo y no debo. Sabes todo eso, y precisamente porque lo sabes, 
sabes que te amo.

Para todas estas cosas, los labios se quedan cortos, las palabras guardan silencio. Se vuelve, entonces, un tiempo de recogimiento, de soledad, de confesión, sin máscaras; tiempo simplemente para estar, cansados tantas veces al final de la jornada, con muchas preguntas y pocas respuestas. En el fondo del alma se enciende una luz, porque comprendemos que aquel cansancio, malestar o dolor, es el yugo suave y ligero con el que el Señor arropa a sus amigos.

\section{Humildad: Andar en Verdad}

Una vez estaba yo considerando por qué razón era nuestro Señor tan amigo de esta virtud de la humildad, y púsoseme delante a mi parecer sin considerarlo, sino de presto esto: que es porque Dios es suma Verdad, y la humildad es andar en verdad, que lo es muy grande no tener cosa buena de nosotros, sino la miseria y ser nada; y quien esto no entiende, anda en mentira. A quien más lo entienda agrada más a la suma Verdad, porque anda en ella. Plegue a Dios, hermanas, nos haga merced de no salir jamás de este propio conocimiento, amén. (p. 255)

$\mathrm{H}$ umildad, andar en Verdad. El Oráculo de Delfos, desde épocas inmemoriales, ponía como inicio de la sabiduría conocerse a sí mismos. Han pasado los siglos y este sabio consejo sigue siendo el inicio de la sabiduría. Tarea interminable. Los poetas lo han cantado: “¿Quién te va a ti a conocer en lo que callas, o en esas palabras con que lo callas?” (Salinas, 1997, p. 131). El ser humano no se contenta ni con tu verdad ni con mi verdad, aspira a más, desea llegar a conocer la Verdad, aunque esta se muestre esquiva y solo se acceda a ella a cucharitas.

Conocerse a sí mismos, ser transparentes a la propia mirada, conocerse y no horrorizarse, conocerse y no ufanarse, andar en verdad. San Juan Pablo II repetía una vez y otra que solo Cristo revela al hombre quién es el hombre. Esto, santa Teresa de Jesús lo sabía muy bien y por eso se miraba a sí misma con los ojos de Cristo. Y ahora el papa Francisco, a propósito de la escena del joven rico que le pregunta al Señor qué más podía hacer, reparaba 
en cómo sería la mirada de Cristo.

En más de una ocasión nos puede resultar difícil sostener su mirada. Nos pasa lo que a Adán y Eva después del pecado original: tenían vergüenza y no querían ser mirados por el Dios del Edén. Esfuerzo inútil porque todo está abierto y desnudo a los ojos del Primer Vidente. Humildad, andar en verdad, mirarnos con los ojos de Cristo y pedirle a Él que nos ayude, que nos haga limpios de corazón para ver ese algo divino que se esconde en las cosas ordinarias de nuestra vida.

\section{Oración y Virtudes}

Torno a decir, que para esto es menester no poner vuestro fundamento sólo en rezar y contemplar; porque, si no procuráis virtudes y hay ejercicio de ellas, siempre os quedareis enanas; $y$ aun plegue a Dios que sea sólo no crecer, porque ya sabéis que quien no crece, descrece; porque el amor tengo por imposible contentarse de estar en un ser, adonde le hay. (p. 304)

1 encanta la expresión que usa la santa: sin virtudes nos quedamos enanos. Más aún, también en las virtudes. No hay cosecha que se guarde en los graneros para el resto de la vida. Por un tiempo se puede vivir de esas rentas espirituales, pero en un abrir y cerrar de ojos esas rentas se acaban y, al poco tiempo, se termina viviendo del cuento. Oración un día y otro, con ganas o sin ganas, con agenda llena o vacía, con depre o sin depre, con sol o con lluvia.

Con las virtudes, lo mismo. La vida buena se compone de pequeñas virtudes, entre ellas orden, puntualidad, honestidad, amabilidad, delicadeza, paciencia, alegría. La virtud es el camino, la oración nos acerca al cielo. Las virtudes nos hacen más humanos. Actos buenos repetidos una y otra vez marcan el camino al andar. Hemos de transitar mucho para que se haga el camino. En cambio, los actos malos, repetidos una y otra vez, no hacen camino, hacen autopistas. Sobre lo último, basta recordar la lectura de El retrato de Dorian Gray, un mapa del deterioro del alma. 


\section{Servicio}

Asi que, hermanas, para que lleve buenos cimientos, procurad ser la menor de todas y esclava suya, mirando cómo o por donde las podéis hacer placer y servir; pues lo que hiciereis en este caso, hacéis más por vos que por ellas, poniendo piedras tan firmes, que no se os caiga el castillo. (p. 304)

Cervicio, por doquier se oye de esta palabra. En las empresas, el área de servicios ha crecido $\checkmark$ muchísimo y cada persona busca el buen servicio. En nuestro caso, la Iglesia define al papa como el Siervo de los siervos de Dios. Asimismo, la Virgen María en la Anunciación se llama a sí misma la anchilla Domini, la esclava, la sierva del Señor. También el papa Francisco repite una vez y otra que la mejor expresión del poder es el servicio. Y a san Josemaría le gustaba decir que "para servir, servir" (Escrivá de Balaguer, 1999, n 50).

A todos nos queda claro que no basta tener buenas intenciones ni un corazón servicial. El servicio requiere tener las competencias adecuadas para convertir el ideal de entrega en una obra eficaz. Servir, querer servir, saber servir. El servicio no se improvisa ni se reduce solo a técnicas. Es, en primer lugar, expresión del alma, esponjada cuando se da porque "la monedita del alma se pierde si no se da” (Machado, 1981, p. 103). Pupilas dilatadas por el amor, los ojos del alma bien abiertos para ver las necesidades de los nuestros y los cercanos. Servir, salir de sí mismo, abrir las puertas, ir a las periferias existenciales. Descubrir dónde falta el calor humano. Compartir silencio. Acompañar al amigo aunque sean miles los kilómetros que nos separan. La oración llega allí donde el brazo se queda corto.

\section{No Queráis Tanto que os Quedéis sin Nada}

T o perfecto es enemigo de lo bueno. Para "don perfecto" o para "dońa perfecta" cualquier

Ulogro es insuficiente. Pero, a base de descartar objetivos factibles, aunque no óptimos, lo que tiene por delante es un desierto. Suele pasar que "la que nace, es la rosa inesperada; la que muere, es la rosa consentida” (Adán, 1980, p. 104). La rosa real es la del jardín, unas veces de colores encendidos y aromas embriagadores, otras de colores opacos y casi sin aroma. 
No es el príncipe azul el que llega, ni la joven rica, inteligente y guapa la que toca la puerta. No somos ni Romeo, ni Julieta; somos lo que somos. Queridos y amados por el Dios de Abraham y de Isaac desde toda la eternidad; llamados a ser felices aquí y Allá. Aquí diseñamos y labramos la biografía personal con sus claroscuros naturales. Queremos y podemos aunque no podemos todo. Queremos mucho, pero no lo podemos todo.

Sobre esto nos viene bien, entonces, volver a oír el consejo del viejo Aristóteles: "Hombre y mujer prudente es como el buen zapatero que hace el mejor calzado con el cuero que se le da" (Ética nicomáquea, I, 10, 1101 a4). No queramos tanto, que nos quedemos sin nada...

\section{No Pensar Mucho, sino Amar Más}

No está la cosa en pensar mucho, sino en amar mucho, $y$ asi, lo que más os despertare a amar, eso haced. Quizá no sabemos qué es amar, y no me espantaré mucho, porque no está en el mayor gusto, sino en la mayor determinación de desear contentar en todo a Dios y procurar en cuanto pudiéramos no le ofender, y rogarle que vaya siempre adelante la honra y la gloria de su Hijo y el aumento de la Iglesia Católica. Estas son las señales del amor, y no penséis que está la cosa en no pensar otra cosa y que si os divertís un poco va todo perdido. (p. 82)

\footnotetext{
mar, ya quisiéramos amar y ser amados, vivir y morir de amor. Paul Claudel (186811955) narra en una de sus más grandes obras de teatro, El zapato de raso, las venturas y desventuras de don Rodrigo y dońa Proeza. Ella está casada con don Pelayo, pero a quien ama es a don Rodrigo. Sale en su busca, pero antes, se descalza y con el zapato de raso en su mano, se dirige a la Virgen y le dice lo siguiente:
}

Por eso, cuando aún estoy a tiempo, con mi corazón en una mano y mi zapato en la otra, en las vuestras me pongo. ¡Virgen madre, os entrego mi zapato! ¡Virgen madre, guardad en vuestra mano mi desdichado pie! Os advierto que al punto voy a daros la espalda y a actuar contra vos con todo empeño. Pero, cuando trate de lanzarme hacia el mal, ¡que sea cojeando! Cuando pretenda franquear la barrera que vos me habéis tendido, ique haya de hacerlo con un ala rota! (Claudel, 2011, p.43) 
A don Rodrigo y doña Proeza resistir en el bien les costó Dios y su ayuda. Y por eso, cuando la pasión aún no había invadido la cordura, sale a relucir la buena madera de dońa Proeza por aquello de que "el que tuvo, retuvo" y se aferra a la mano que le extiende comprensiva la Virgen que guarda su casa. Sin embargo, no es la única que utiliza la estrategia de atarse. Lo hace también Ulises, camino a Ítaca, su hogar, en donde le espera la paciente Penélope y su hijo Telémaco. Solo le falta el último trecho de su larga y accidentada odisea. Debe pasar cerca de la isla de las sirenas, cuyo canto hace enloquecer a los marineros quienes se lanzan al mar perdiendo la vida en las peñas. El gran Ulises desconfía de sus fuerzas y se hace atar muy bien al mástil de la nave. A sus hombres les manda tapar sus oídos. Precauciones de un héroe que se sabe de carne y hueso.

Ahora bien, es tremendo misterio el del mal, acechando de continuo en más de una esquina. No pienso solo en el terrible Jack el Destripador. También están esas curiosas mañanas o noches en las que se nos da por ser malos, como si quisiéramos tomarnos un descansito del bien que hacemos.

Resistir en el bien, no cansarse de hacer el bien, ¡cosas serias! Doña Proeza, saca fuerzas de su flaqueza y es capaz de ponerse trabas a sí misma. De ese modo se apresta a hacer el mal con el ala rota. Pero lo contario es, incluso, más verdadero: se puede hacer el bien a la pata coja. No es el mejor modo, desde luego, mas es una buena forma de permanecer en el camino. Ya vendrán días mejores: ni solo rosas, ni únicamente temblores. Tal como dijo san Juan Pablo II, "Por eso, toda vida humana, singular o colectiva, aparece como una lucha, ciertamente dramática, entre el bien y el mal, entre la luz y las tinieblas" (Juan Pablo II, 2005, pp. 32-33). Más aún, el mal busca "la penumbra que esconde en su sombra venganza y traición”, como acertadamente reza el vals de Pinglo. El bien gusta del aire fresco y el agua limpia.

Amar, dice santa Teresa, es contentar en todo a Dios. Meta grande para nuestro empeño y a lo cual solamente agrego:

¿Amor? Amor el que me das,

Porque Tú pones en mí el amor con que te amo.

Sé que vivo de prestado

Y en el amor ando falto de peso.

Pon el faltante, mi bien,

Y no te canses de amarme. 


\section{Paciencia}

No da Dios más de lo que se puede sufrir, y da Su Majestad primero la paciencia; mas de otros grandes en lo ordinario y enfermedades de muchas maneras. (p. 160)

hora puede hablarse sobre cómo tratamos la cercanía con el dolor, el sufrimiento propio
y de los seres queridos. Los decaimientos del ánimo, el miedo real o imaginario ante las enfermedades, el desasosiego vivencial y tantos otros contratiempos nos hacen palpar la fragilidad de nuestra condición. Mas, las respuestas que solemos dar a esas situaciones, aunque diversas, no todas dan en la diana del problema.

Para el que no tiene fe en Dios, el agnóstico, el ateo o simplemente para el que tiene una fe incipiente, al dolor propio y ajeno se suma otro dolor, el sinsentido, tan próximo a la angustia y a la desesperación. Solo queda aguantar, esperar a que pase el mal rato, acostumbrarse a la pena y seguir pateando la vida. Ante el dolor, la enfermedad, la depresión, se busca al médico y se toma un fármaco. Es una mala noche en una mala posada que no cuenta, no forma parte de la felicidad. Cuantas menos malas noches de pesadilla, mejor. A lo sumo se puede llegar a la resignación. Es la actitud del estoico: aguantar a pie firme, como si dijera para sí mismo "si hemos nacido para sufrir, suframos nomás".

El que tiene fe, por el contrario, ama al mundo apasionadamente. Sabe que el mundo es bueno y se sabe hijo de Dios, de un Dios que es Padre, cuyas delicias es estar con los hijos de los hombres, a quienes ama y con quienes juega. Las alegrías y las penas se aclaran cuando se ven los episodios de la vida de Jesucristo: Tabor (transfiguración gloriosa) y Calvario (pasión, muerte y resurrección). Esa es la vida del Dios hecho hombre quien nos revela que esa es nuestra vida, también. Ante las alegrías, gracias Señor. ¿Y ante las penas, las preocupaciones, las depresiones? El Señor se adelanta y nos dice, como a sus discípulos, en plena tempestad en el mar de Galilea, “Tened confianza. Soy Yo, no tengáis miedo” (Mc 14, 27). Aprendemos, entonces, a encontrar la paz del alma en medio de la tribulación diciendo "bendito sea el dolor, santificado sea el dolor" (Escrivá de Balaguer, 1939, p. 57). Sí, allí está, igualmente, la mano del Señor, es Cristo que pasa a nuestro lado.

Para esos momentos de insomnio, de falta de paz en el alma, vienen como anillo al dedo las oraciones conmovedoras del siguiente salmo: "El Señor es mi pastor, nada me falta. 
SIGNOS

/En verdes praderas me hace reposar; / me conduce hacia fuentes tranquilas /y restaura mis fuerzas" (Sal 23). Del mismo modo, como decía san Juan Pablo II en su Tríptico romano, para una mujer y un hombre de fe la vida en todas sus coloraciones "tiene sentido... tiene sentido..." (Juan Pablo II, 2003, p. 21). El cuadro de nuestra vida recoge en sus trazos luces y sombras. El dolor no está fuera del marco, forma parte del mismo lienzo. 


\section{Referencias}

Claudel, P. (2011). El zapato de raso. Madrid, España: Editorial Encuentro.

Escrivá de Balaguer, J. (1939). Camino. Madrid, España: Ediciones Rialp.

Escrivá de Balaguer, J. (1999). Homilía En el taller de José. En Es Cristo que pasa. Madrid, España: Ediciones Rialp.

Machado, A. (1981). Soledades. Poesías de la guerra. Madrid, España: Ediciones Busma.

Juan Pablo II. (2003). Tríptico romano. Madrid, España: Universidad Católica San Antonio.

Juan Pablo II. (2005). Memoria e identidad. Conversaciones al filo de dos milenios. (Trad. B.

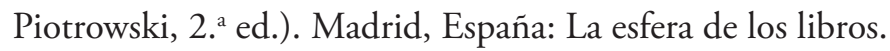

Salinas, P. (1997). La voz a ti debida. Madrid, España: Ediciones Cátedra.

Santa Teresa de Jesús. (1944). El castillo interior o Las moradas. Barcelona, España: Montaner y Simón.

Santa Teresa de Jesús. (2012). Libro de la vida. En Obras completas. Madrid, España: B.A.C.

Silva-Santisteban, R. (Ed.). (1980). Martín Adán. Obra poética. Lima, Perú: Ediciones Edubanco. 